\title{
Low plasma zinc concentrations in pediatric patients with cirrhosis
}

\author{
Ana C. R. Schneider, ${ }^{1}$ Raquel B. Pinto, ${ }^{2}$ Pedro E. Fröehlich, ${ }^{3}$ \\ Thais O. Hammes, ${ }^{4}$ Themis R. da Silveira $^{5}$
}

\begin{abstract}
Objective: To determine plasma zinc concentrations in children and adolescents with cirrhosis and to investigate the association between these results and dietary zinc intake, anthropometric data, and severity of liver disease.

Methods: Plasma zinc concentration was assessed by atomic absorption spectrophotometry in 30 children and

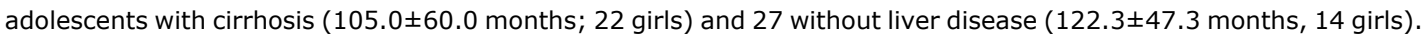
Dietary zinc data were evaluated by 3-day food intake records. Anthropometry measures included height, weight, skinfold thickness, brachial circumference, and upper arm muscle size. Severity of liver disease was classified according to the Child-Pugh, MELD, and PELD criteria.

Results: The mean ( \pm standard deviation) plasma zinc concentrations in control subjects and patients were $105.69 \pm 19.46$ and $75.44 \pm 24.45 \mu \mathrm{g} / \mathrm{dL}$, respectively $(p<0.001)$. No associations were found between anthropometric measures, dietary zinc intake, and plasma zinc concentration. There was statistical difference related to plasma zinc concentrations between Child-Pugh B $+C$ patients and control subjects $(p<0.001)$, and concerning PELD, between patients below the cutoff score of 15 and those above $(p=0.002)$.

Conclusions: The prevalence of hypozincemia was $43 \%$ for patients with cirrhosis. Although low plasma zinc concentration was associated with more severe liver disease, it was present even in some Child-Pugh A patients. Therefore, zinc supplementation should be considered for cirrhotic children.
\end{abstract}

J Pediatr (Rio J). 2009;85(4):359-364: Zinc, liver cirrhosis, anthropometry, child.

\section{Introduction}

Studies have confirmed the importance of zinc as a fundamental trace element in human metabolism.1,2 Zinc affects growth and plays a role in the synthesis of proteins and nucleic acids, as well as in the synthesis of insulinlike growth factor 1 (IGF-1) and in its effects on target tissues. ${ }^{3}$ Zinc deficiency predisposes to growth retardation, neurosensory deficit, disorders in the metabolism of several hormones and enzymes that participate in growth and bone development, wound healing retardation, skin lesions, delayed sexual maturation, and immunodeficiency. ${ }^{4-6}$ This trace element also acts as an antioxidant by means of two different mechanisms: protection against oxidation and inhibition of the production of reactive types of oxygen by transition metals, such as iron and copper, both metals linked to liver injury. ${ }^{7,8}$

No consensus has been reached about the causes of zinc deficiency in liver diseases: anorexia and reduced intake of animal proteins, increase in cytokines or hormones that

1. Nutricionista. Mestre, Pediatria, Universidade Federal do Rio Grande do Sul (UFRGS), Porto Alegre, RS, Brazil.

2. Médica Pediatra. Pós-Doutora, Gastroenterologia, UFRGS, Porto Alegre, RS, Brazil.

3. Farmacêutico. Doutor, Ciências Farmacêuticas. Professor, Faculdade de Farmácia, UFRGS, Porto Alegre, RS, Brazil.

4. Nutricionista. Mestranda, Gastroenterologia, UFRGS, Porto Alegre, RS, Brazil.

5. Médica. Doutora, Genética. Professora, Faculdade de Medicina, Hospital de Clínicas de Porto Alegre, UFRGS, Porto Alegre, RS, Brazil.

This study was conducted at Hospital de Clínicas de Porto Alegre, Universidade Federal do Rio Grande do Sul (UFRGS), Porto Alegre, RS, Brazil.

No conflicts of interest declared concerning the publication of this article.

Suggested citation: Schneider AC, Pinto RB, Fröehlich PE, Hammes TO, da Silveira TR. Low plasma zinc concentrations in pediatric patients with cirrhosis. J Pediatr (Rio J). 2009;85(4):359-364.

Manuscript submitted Apr 16 2009, accepted for publication May 202009

doi:10.2223/JPED.1918 
may affect zinc metabolism, increase of renal loss of zinc and also portal hypertension, which is responsible for poor absorption of nutrients. ${ }^{9}$

Some alterations of patients with cirrhosis may be associated with zinc deficiency: alopecia, wound healing disorders, lack of appetite, hypogeusia, gonadal growth retardation, 10 and it is also associated with hepatic encephalopathy. ${ }^{11,12}$ A study with adult patients with decompensated cirrhosis found that these patients have plasma zinc concentrations significantly lower than patients with compensated disease, and that zinc concentrations are negatively associated with fasting ammonia concentrations. 13

Because of its role during the growth period and for immunocompetence, we evaluated and compared zinc concentrations in children and adolescents with liver disease.

\section{Patients and methods}

This case-control study was carried out from August 2003 to July 2005, 57 children and adolescents were examined. The participants were divided into two groups. Group 1 was composed of 30 children and adolescents with cirrhosis regularly seen at the Outpatient Service of the Pediatric Gastroenterology Unit, Hospital de Clínicas de Porto Alegre, Porto Alegre, Brazil. Group 2 was composed of 27 children and adolescents without liver disease and apparently healthy, selected during routine blood collection at the Clinical Laboratory, Hospital de Clínicas de Porto Alegre, Porto Alegre, Brazil.

Cirrhosis diagnosis was confirmed by liver function tests (prothrombin time, serum albumin, aminotransferase activity, serum bilirubin, gamma-glutamyl-transpeptidase and alkaline phosphatase), endoscopy results (esophageal varices), ultrasound studies (liver with heterogeneous echogenicity and signs of portal hypertension) and by histological exam (nodular formation and fibrosis in liver biopsy). Etiologic factors of cirrhosis were determined for 21 patients $(70.0 \%)$ but were impossible to identify for nine of them. In 10 patients, the cause of cirrhosis was biliary atresia; in nine, autoimmune diseases; in one, Langerhans histiocytosis; and in one, alpha-1-antitrypsin deficiency.

The severity of liver disease was evaluated using the Child-Pugh, the Pediatric End-Stage Liver Disease (PELD), and the Model for End-Stage Liver Disease (MELD) criteria. According to the Child-Pugh criteria,14 15 patients were classified as A, 10 as B, and five as C. In the Child-Pugh classification, mild disease is classified as $A$, moderate disease as $B$, and severe disease as $C$. We used the MELD for patients aged 12 and older and the PELD for those aged 11 and younger. ${ }^{15}$ Higher values indicate more severe disease. A score of 15 is the cutoff point for these criteria. Fifteen out of 20 patients younger than 12 years had a
PELD score below 15, and five had a PELD score above 15. Only one out of 10 patients older than 12 years had a score above 15.

Exclusion criteria were the same for the patients and control subjects: intake of mineral supplements (zinc, copper or both), oral contraceptives, antibiotics up to 15 days before blood collection, lactulose, vegetarianism, gestation, blood transfusion less than 1 month before collection, infections, smoking and diagnosis of Wilson's disease.

This study was approved by the Ethics Committee of Hospital de Clínicas de Porto Alegre. The participants' guardians signed an informed consent form.

\section{Dietary intake data and anthropometry}

Patients and control subjects filled out a dietary questionnaire to determine dietary zinc intake ( 2 weekdays and 1 weekend day). Patients underwent anthropometric tests that measured weight, height, brachial circumference $(B C)$, triceps skinfold (TSF) and upper arm muscle size (UAMS). Anthropometric indices - weight/age (W/A) and height/age $(\mathrm{H} / \mathrm{A})$ - were calculated using the $\mathrm{z}$ score and the NutStat software (Epi-Info 3.6, CDC/WHO 2000). BC, TSF and UAMS were calculated according to the Frisancho ${ }^{16}$ equations and compared with the normal values in the Frisancho ${ }^{17}$ tables.

\section{Plasma zinc}

Material for fasting plasma zinc measurements was collected between 7:00 and 10:00 a.m. All the material used in collection and storage was free of metal contamination: sodium heparin tubes (367735, BD Vacutainer ${ }^{\circledR}$ ), powderless silicone gloves, pipette tips and tubes previously sterilized with deionized water and nitric acid and dried in oven at $60^{\circ} \mathrm{C}$. Hemolyzed samples were excluded. Blood collected was immediately centrifuged at 3,000 rpm for $10 \mathrm{~min}$. After centrifuging, plasma was pipetted, placed in test tubes (Eppendorf Tips, 50-1,000 $\mu \mathrm{L}$ ) and stored at $-20^{\circ} \mathrm{C}$. Plasma samples analysis were performed on an automated PerkinElmer Analyst 300 atomic absorption spectrophotometer (Welleslay, MA, USA), and the coefficient of variation was below $10 \%$. The cutoff point for fasting zinc deficiency was $70 \mu \mathrm{g} / \mathrm{dL} .{ }^{18}$ This cutoff point is two standard deviations (SD) below the population mean, and concentrations between 70 and $150 \mu \mathrm{d} / \mathrm{dL}$ were classified as normal.

\section{Statistical analysis}

The Student $t$ test was used to compare means of patients with cirrhosis and control subjects and PELD and MELD scores. One-way analysis of variance and the Tukey test were used to determine differences between plasma zinc concentrations and severity of cirrhosis according to the Child-Pugh score. The chi-square test and the Fischer 
test were used to compare categorical variables. The Pearson coefficient was calculated to determine correlations. Microsoft Excel for Windows ${ }^{\circledR}$ was used for the database, and the Statistical Package for Social Sciences ${ }^{\circledR}$ (SPSS 12.0), for statistical tests. The level of significance was established at $\mathrm{p}<0.05$.

\section{Results}

Fasting blood samples were obtained from 30 patients (105.0 \pm 60.0 months; 22 girls) and 27 control subjects (122.3 \pm 47.3 months; 14 girls). The comparison of age $(p=0.23)$ and sex $(p=0.26)$ for patients and controls did not show any statistically significant difference. Plasma zinc concentrations, the results of the laboratory assays and anthropometric indices are summarized in Table 1.

\section{Dietary intake data and anthropometry}

The assessment of dietary zinc intake showed that $18(66.6 \%)$ of the 27 patients that filled out the intake questionnaire had an adequate dietary zinc intake for the age. The analysis of the questionnaires filled out by control subjects (20/27) showed an adequate dietary zinc intake. No patient or control subject had diets with only whole foods or exclusively vegetarian, nor any type of diet that contained components that may compromise dietary zinc absorption.

The $z$ score of W/A index ranged from -5.20 to 2.15 $(-0.53 \pm 1.46)$. The $H / A$ index had $z$ scores ranging from -3.92 to $1.76(-0.81 \pm 1.23)$. $Z$ scores below -2 were found for $5 / 30$ patients $(16.6 \%)$ in the W/A index, and $4 / 30$ patients $(13.3 \%)$ in the H/A index. Measures of $B C$, TSF and UAMS below the 5th percentile were found for $5 / 29(17.2 \%), 8 / 29(27.6 \%)$, and $5 / 29$ patients $(17.2 \%)$, respectively.

\section{Plasma zinc}

The analysis of plasma zinc in children and adolescents with cirrhosis showed that $43 \%(13 / 30)$ had concentrations below $70 \mu \mathrm{g} / \mathrm{dL}$. Mean \pm SD and range were $75.44 \pm 24.45$ $\mu \mathrm{g} / \mathrm{dL}$, ranging between 35.07 and $132.00 \mu \mathrm{g} / \mathrm{dL}$. Results for control subjects were normal (mean $\pm \mathrm{SD}=105.69 \pm 19.46$ $\mu \mathrm{g} / \mathrm{dL})$. The comparison of the two groups revealed a significant difference $(p<0.001)$ (Figure 1$)$.

Table 1 - Characteristics of patients classified according to plasma zinc concentrations

\begin{tabular}{|c|c|c|c|c|}
\hline Characteristics & $\begin{array}{c}\text { All patients }(n=30) \\
\text { mean } \pm \text { SD }\end{array}$ & $\begin{array}{l}\text { Low zinc } \\
(n=13)\end{array}$ & $\begin{array}{l}\text { Normal zinc } \\
\qquad(n=17)\end{array}$ & $\mathbf{p}^{*}$ \\
\hline Age (months) & $105.0 \pm 60.0$ & $88.8 \pm 62.9$ & $117.29 \pm 56.58$ & 0.20 \\
\hline $\operatorname{Sex}(M / F)$ & $8 / 22$ & $4 / 9$ & $4 / 13$ & 0.97 \\
\hline Plasma zinc $(\mu \mathrm{g} / \mathrm{dL})$ & $75.44 \pm 24.45$ & $53.72 \pm 9.99$ & $92.05 \pm 19.21$ & 0.001 \\
\hline Total bilirubin (mg/dL) & $7.37 \pm 11.30$ & $14.99 \pm 13.99$ & $1.55 \pm 1.28$ & 0.005 \\
\hline Conjugated bilirubin (mg/dL) & $3.96 \pm 6.37$ & $8.4 \pm 7.7$ & $0.54 \pm 0.53$ & 0.003 \\
\hline Albumin $(g / d L)$ & $3.9 \pm 0.8$ & $3.2 \pm 0.79$ & $4.4 \pm 0.40$ & 0.001 \\
\hline Creatinine $(\mathrm{mg} / \mathrm{dL})$ & $0.59 \pm 0.15$ & $0.62 \pm 0.19$ & $0.56 \pm 0.13$ & 0.36 \\
\hline Prothrombin time (seconds) & $4.5 \pm 4.6$ & $7.04 \pm 5.44$ & $2.64 \pm 2.79$ & 0.013 \\
\hline AST $(U / L)$ & $174.3 \pm 216,5$ & $265.5 \pm 293.4$ & $104.6 \pm 91.7$ & 0.038 \\
\hline $\operatorname{ALT}(U / L)$ & $131.2 \pm 163.2$ & $179.3 \pm 219.2$ & $94.3 \pm 94.4$ & 0.14 \\
\hline Gamma-glutamyl-transpeptidase (U/L) & $152.6 \pm 215.67$ & $111.1 \pm 155.4$ & $188.6 \pm 256.97$ & 0.53 \\
\hline Alkaline phosphatase (U/L) & $934.8 \pm 527.0$ & $943.7 \pm 437.9$ & $926.6 \pm 615.1$ & 0.93 \\
\hline \multicolumn{5}{|l|}{ Anthropometric data } \\
\hline WAZ & $-0.53 \pm 1.46$ & $-0.62 \pm 1.96$ & $-0.46 \pm 0.98$ & 0.77 \\
\hline $\mathrm{HAZ}$ & $-0.81 \pm 1.23$ & $-0.74 \pm 1.48$ & $-0.86 \pm 1.04$ & 0.79 \\
\hline $\mathrm{BC}(\mathrm{n}=27)^{\dagger}$ & & 17.5 & 25 & 0.13 \\
\hline $\operatorname{TSF}(n=27)^{\dagger}$ & & 10 & 25 & 0.08 \\
\hline UAMS $(n=27)^{\dagger}$ & & 17.5 & 25 & 0.19 \\
\hline
\end{tabular}

$\mathrm{ALT}=$ alanine aminotransferase $\mathrm{AST}=$ aspartate aminotransferase; $\mathrm{BC}=$ brachial circumference; $\mathrm{HAZ}=$ height for age $\mathrm{z}$ Score $; \mathrm{SD}=\mathrm{standard}$ deviation; $\mathrm{TSF}=\mathrm{triceps}$ skinfold; UAMS = upper arm muscle size; WAZ = weight for age $\mathrm{z}$ score.

ANOVA and Tukey test.

* Normal vs. low zinc.

$\uparrow$ Median. 


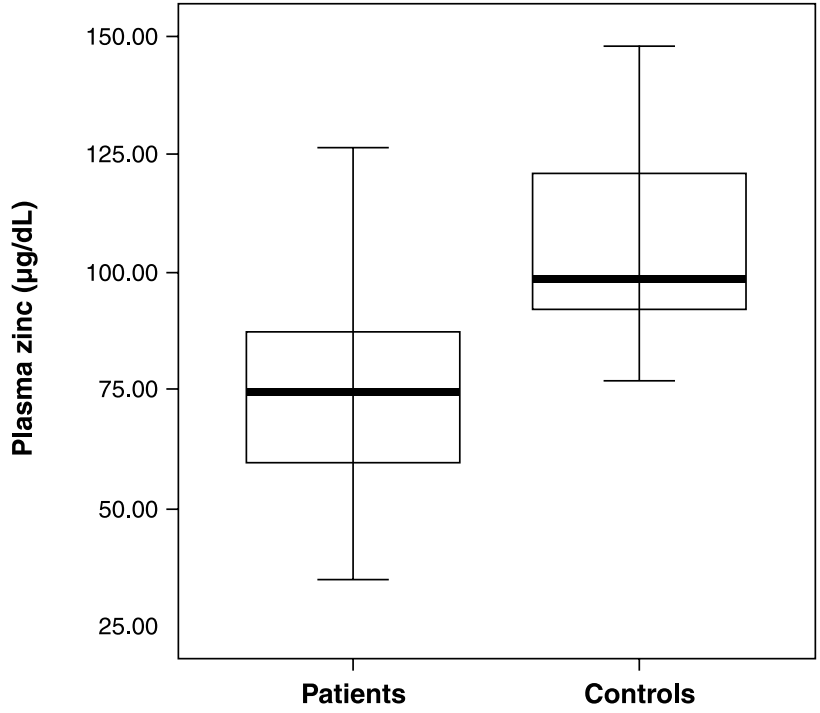

Figure 1 - Comparison of plasma zinc concentrations between patients $(n=30)$ and control subjects $(n=27)$ $(p<0.001)$

There were no associations between anthropometric measures and plasma zinc concentrations or between dietary zinc intake and plasma zinc concentrations. The comparison of plasma zinc concentrations between patients with sufficient $(78.54 \pm 25.01 \mu \mathrm{g} / \mathrm{dL})$ and insufficient dietary intake $(69.40 \pm 22.95 \mu \mathrm{g} / \mathrm{dL})$ did not reveal any statistically significant difference $(p=0.38)$.

The comparison of liver disease severity according to the Child-Pugh criteria and plasma zinc concentrations yielded the following results: mean \pm SD and the range of plasma zinc in Child-Pugh A patients were 91.26 \pm 22.88 $\mu \mathrm{g} / \mathrm{dL}(58.59-132.0 \mu \mathrm{g} / \mathrm{dL}) ;$ in B patients, $64.62 \pm 14.98$ $\mu \mathrm{g} / \mathrm{dL}(35.07-81.91 \mu \mathrm{g} / \mathrm{dL}) ;$ and in C patients, $49.63 \pm 8.97$ $\mu \mathrm{g} / \mathrm{dL}(42.43-64.20 \mu \mathrm{g} / \mathrm{dL})$. The number of patients with low plasma zinc concentration classified as Child-Pugh $A$ was $3 / 15$, as $B, 5 / 10$, and as $C, 5 / 5$. For statistical analysis, data for patients classified as Child-Pugh $B$ and $C$ were put in the same group (Figure 2 ). The results of the comparisons between patients and control subjects were as follows: $105.69 \pm 19.45 \mu \mathrm{g} / \mathrm{dL}$ for controls vs. $91.26 \pm 22.88 \mu \mathrm{g} / \mathrm{dL}$ for children classified as Child-Pugh A (ANOVA and Tukey test, $p=0.038) ; 105.69 \pm 19.45 \mu \mathrm{g} / \mathrm{dL}$ for controls vs. $59.62 \pm 14.85 \mu \mathrm{g} / \mathrm{dL}$ for children classified as Child-Pugh $\mathrm{B}+\mathrm{C}$ (ANOVA and Tukey test, $\mathrm{p}<0.001$ ); 91.26 \pm 22.88 $\mu \mathrm{g} / \mathrm{dL}$ for Child-Pugh A vs. $59.62 \pm 14.85 \mu \mathrm{g} / \mathrm{dL}$ for ChildPugh $B+C$ (ANOVA and Tukey test, $p<0.001$ ). There was no statistical difference between Child-Pugh $A$ patients and control subjects $(p=0.038)$, but there was a statistic difference between Child-Pugh $B+C$ patients and control subjects $(p<0.001)$ and between Child-Pugh $B+C$ and Child-Pugh A patients ( $p<0.001)$.
For the analysis of the association between the PELD and MELD scores and plasma zinc concentration, the cutoff point was 15 . Concerning the PELD, mean plasma zinc concentration in the 15 patients with scores below the cutoff point was $81.80 \pm 25.41 \mu \mathrm{g} / \mathrm{dL}$. In the five patients with scores above the cutoff point, plasma zinc concentration was $50.19 \pm 8.74 \mu \mathrm{g} / \mathrm{dL}(\mathrm{p}=0.002)$. The mean concentration of zinc in the nine patients with MELD score < 15 was $82.17 \pm 20.89 \mu \mathrm{g} / \mathrm{dL}$. A statistical comparison with MELD score $>15$ was not possible since there was only one patient in this category.

There was a negative correlation between plasma zinc concentration and total $(r=-0.59)$ and direct $(r=-0.60)$ bilirubin. But the most significant association was between hypozincemia and conjugated hyperbilirubinemia ( $p<0.001)$. Albumin correlated positively $(r=0.69)$ with plasma zinc, but $4 / 13$ patients had normal albumin levels and low zinc concentrations.

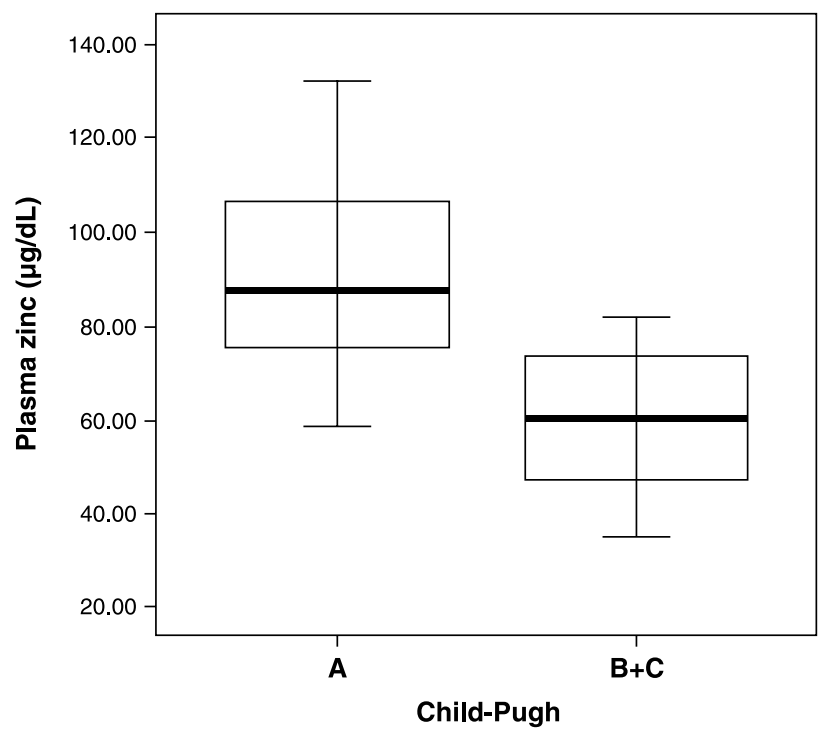

Figure 2 - Comparison of plasma zinc concentrations between Child-Pugh $A(n=15)$ and Child-Pugh $B+C$ patients $(n=15)(p<0.001)$

\section{Discussion}

The liver is important for the regulation of zinc homeostasis, while zinc is necessary for proper liver function. Decreased zinc levels have been implicated in both acute and chronic liver disease states, but its hepatoprotective property has not been fully elucidated. ${ }^{9}$ This study found a significant plasma zinc deficiency $(43 \%)$ in pediatric patients with liver cirrhosis when compared with normal control subjects in the same age group. The results of 
this study are compatible with those reported by Chin et al., ${ }^{19}$ who evaluated the nutritional status of 27 children awaiting liver transplantation and found hypozincemia in $42 \%$ of the patients.

There is no consensus about the relationship of severity of the liver disease and serum/plasma zinc concentration, both in adults and pediatric patients. A study with adult patients with cirrhosis found an association between zinc deficiency and the increase in the severity of cirrhosis, 9,20 but another study did not. ${ }^{21}$ Hambidge et al., ${ }^{22}$ studying children with biliary atresia, did not find significant differences for plasma zinc, hepatic function and biliary drainage. Sato et al. ${ }^{23}$ evaluated copper and zinc in children with biliary atresia at different stages and found a decrease in liver and serum zinc and an increase in copper concentrations as liver impairment progressed. In our study, the mean plasma zinc in total patients group with cirrhosis was within normal values; however, when patients were separated into groups according to the Child-Pugh criteria, patients classified as $A$ had mean concentrations within normal values, but $B$ and $C$ patients had means below the cutoff point. The same trend was found when the PELD was used - patients with scores below 15 had a normal mean concentration, whereas those with a score above 15 had lower plasma zinc concentrations. The association with severity of liver disease according to the Child-Pugh and PELD revealed that plasma zinc deficiency was associated with the worst prognoses determined by these criteria.

A significant correlation between zinc and albumin was found in our study and by other authors who studied patients with liver disease and also cystic fibrosis. 24,25 It is interesting to notice that even in patients with low albumin concentrations the supplementation may correct hypozincemia. 26,27

Low plasma zinc in patients with liver cirrhosis does not seem to be associated with the diet. This study did not find a significant statistical difference, although 9/27 (45\%) patients reported insufficient dietary zinc intake according to the recent Recommended Dietary Allowance (RDA). We also noted that $5 / 6$ patients with more advanced cirrhosis had zinc intake over the RDA recommendations values, nevertheless presented low plasma zinc concentrations. These results may indicate that the zinc deficiency in these patients is related to the liver impairment and not to dietetic zinc intake.

A meta-analysis of randomized and controlled studies of prepuberty children found that zinc supplementation resulted in weight and height gains in children with zinc deficiency. ${ }^{28}$ A positive association between supplementation and the increase in growth velocity in children was also observed by Nakamura et al. ${ }^{29}$ and by Michaelsen et al. 30 Our study did not find any association between anthropometric data and plasma zinc concentrations, which is in agreement with other studies of pediatric patients with cirrhosis. ${ }^{19,24}$ In a recent study that evaluated plasma zinc concentration in pediatric patients with cystic fibrosis, the body mass index was not correlated with low plasma zinc concentrations as well. 25

Trials of zinc supplementation have shown positive effects on clinical outcomes and growth, especially among children who are stunted. 31,32 Hambidge et al., ${ }^{22}$ studying children with biliary atresia, considered that the zinc requirement for net absorption would be $40 \%$ greater than that of healthy infants. Considering that the liver impairment affects the zinc metabolism and absorption of dietetic zinc, we believe that zinc supplementation could improve the zinc status of these patients.

\section{Conclusions}

The $43 \%$ prevalence of low plasma zinc concentrations was observed in the present sample of children and adolescents with cirrhosis. There were no associations between dietary zinc intake and nutritional status measured by anthropometry and plasma zinc concentrations. However, this study found lower zinc concentrations associated with an increase in cirrhosis severity. It is important to note that some patients classified as Child-Pugh A and PELD score below 15 also had hypozincemia and, therefore, zinc deficiency should be investigated in all patients regardless of cirrhosis severity. We conclude that zinc should be included among the micronutrients that are given particular consideration in the management of cirrhosis in order to prevent zinc deficiency.

\section{Acknowledgments}

Financial support for this study was provided by the Brazilian Federal Agency for the Improvement of Higher Education (Coordenação de Aperfeiçoamento de Pessoal de Nível Superior, CAPES) and Research Support Fund of Hospital de Clínicas de Porto Alegre (Fundo de Incentivo a Pesquisas do Hospital de Clínicas de Porto Alegre, FIPE).

\section{References}

1. Gibson RS, Hess SY, Hotz C, Brown KH. Indicators of zinc status at the population level: a review of the evidence. Br J Nutr. 2008;99 Suppl 3:S14-23.

2. Heyland DK, Jones N, Cvijanovich NZ, Wong H. Zinc supplementation in critically ill patients: a key pharmaconutrient? JPEN J Parenter Enteral Nutr. 2008;2:509-19.

3. MacDonald RS. The role of zinc in growth and cell proliferation. J Nutr. 2000;130:1500S-8S.

4. Rink $L$, Kirchner $H$. Zinc-altered immune function and cytokine production. J Nutr. 2000;130:1407S-11S.

5. O'Dell BL. Role of zinc in plasma membrane function. J Nutr. 2000;130:1432S-6S.

6. Hambidge KM, Krebs NF. Zinc deficiency: a special challenge. J Nutr. 2007;137:1101-5. 
7. Prasad AS. Clinical, immunological, anti-inflammatory and antioxidant roles of zinc. Exp Gerontol. 2008;43:370-7.

8. Powell SR. The antioxidant properties of zinc. J Nutr. 2000;130:1447S-54S.

9. Stamoulis I, Kouraklis G, Theocharis S. Zinc and the liver: an active interaction. Dig Dis Sci. 2007;52:1595-612.

10. Prasad AS. Zinc deficiency in humans: a neglected problem. J Am Coll Nutr. 1998;17:542-3.

11. Chetri K, Choudhuri G. Role of trace elements in hepatic encephalopathy: zinc and manganese. Indian J Gastroenterol. 2003;22 Suppl 2:S28-30.

12. Morgan MY, Blei A, Grungreiff K, Jalan R, Kircheis G, Marchesini $\mathrm{G}$, et al. The treatment of hepatic encephalopathy. Metab Brain Dis. $2007 ; 22: 389-405$

13. Yoshida Y, Higashi T, Nouso K, Nakatsukasa H, Nakamura SI, Watanabe $A$, et al. Effects of zinc deficiency/zinc supplementation on ammonia metabolism in patients with decompensated liver cirrhosis. Acta Med Okayama. 2001;55:349-55.

14. Pugh RN, Murray-Lyon IM, Dawson JL, Pietroni MC, Williams R. Transection of the oesophagus for bleeding oesophageal varices. Br J Surg. 1973;60:646-9.

15. Policy 3.6 Organ Distribution. 2005. http://www.unos. org/PoliciesandBylaws2/policies/pdfs/policy_8.pdf Access: 13/04/2009.

16. Frisancho AR. Triceps skin fold and upper arm muscle size norms for assessment of nutrition status. Am J Clin Nutr. 1974;27:1052-8.

17. Frisancho AR. New norms of upper limb fat and muscle areas for assessment of nutritional status. Am J Clin Nutr. $1981 ; 34: 2540-5$

18. Trumbo $P$, Yates AA, Schlicker S, Poos M. Dietary reference intakes: vitamin $\mathrm{A}$, vitamin $\mathrm{K}$, arsenic, boron, chromium, copper, iodine, iron, manganese, molybdenum, nickel, silicon, vanadium, and zinc. J Am Diet Assoc. 2001;101:294-301.

19. Chin SE, Shepherd RW, Thomas BJ, Cleghorn GJ, Patrick MK, Wilcox JA, et al. The nature of malnutrition in children with endstage liver disease awaiting orthotopic liver transplantation. Am J Clin Nutr. 1992;56:164-8.

20. Poo JL, Rosas-Romero R, Rodriguez F, Silencio JL, Munoz R, Bourges $\mathrm{H}$, et al. Serum zinc concentrations in two cohorts of 153 healthy subjects and 100 cirrhotic patients from Mexico City. Dig Dis. $1995 ; 13: 136-42$.

21. Loguercio C, De Girolamo V, Federico A, Feng SL, Crafa E, Cataldi $\mathrm{V}$, et al. Relationship of blood trace elements to liver damage, nutritional status, and oxidative stress in chronic nonalcoholic liver disease. Biol Trace Elem Res. 2001;81:245-54.
22. Hambidge KM, Krebs NF, Lilly JR, Zerbe GO. Plasma and urine zinc in infants and children with extrahepatic biliary atresia. J Pediatr Gastroenterol Nutr. 1987;6:872-7.

23. Sato C, Koyama $H$, Satoh $H$, Hayashi $Y$, Chiba $T$, Ohi $R$. Concentrations of copper and zinc in liver and serum samples in biliary atresia patients at different stages of traditional surgeries. Tohoku J Exp Med. 2005;207:271-7.

24. Narkewicz MR, Krebs N, Karrer F, Orban-Eller K, Sokol RJ. Correction of hypozincemia following liver transplantation in children is associated with reduced urinary zinc loss. Hepatology. $1999 ; 29: 830-3$

25. Maqbool A, Schall JI, Zemel BS, Garcia-Espana JF, Stallings VA. Plasma zinc and growth status in preadolescent children with cystic fibrosis. J Pediatr Gastroenterol Nutr. 2006;43:95-101.

26. Zhou Z, Liu J, Song Z, McClain CJ, Kang YJ. Zinc supplementation inhibits hepatic apoptosis in mice subjected to a long-term ethanol exposure. Exp Biol Med (Maywood). 2008;233:540-8.

27. Barve A, Khan R, Marsano L, Ravindra KV,McClain C. Treatment of alcoholic liver disease. Ann Hepatol. 2008;7:5-15.

28. Brown KH, Peerson JM, Rivera J, Allen LH. Effect of supplemental zinc on the growth and serum zinc concentrations of prepubertal children: a meta-analysis of randomized controlled trials. Am J Clin Nutr. 2002;75:1062-71.

29. Nakamura T, Nishiyama S, Futagoishi-Suginohara $Y$, Matsuda I, Higashi A. Mild to moderate zinc deficiency in short children: effect of zinc supplementation on linear growth velocity. J Pediatr. $1993 ; 123: 65-9$

30. Michaelsen KF, Samuelson G, Graham TW, Lonnerdal B. Zinc intake, zinc status and growth in a longitudinal study of healthy Danish infants. Acta Paediatr. 1994;83:1115-21.

31. Fischer Walker CL, Black RE. Functional indicators for assessing zinc deficiency. Food Nutr Bull. 2007;28:S454-79.

32. Ramakrishnan $U$, Nguyen $P$, Martorell R. Effects of micronutrients on growth of children under $5 \mathrm{y}$ of age: meta-analyses of single and multiple nutrient interventions. Am J Clin Nutr. 2009;89:191-203.

Correspondence:

Ana Cláudia Reis Schneider

Laboratório Experimental de Hepatologia e Gastroenterologia

Centro de Pesquisas - Hospital de Clínicas de Porto Alegre

Rua Ramiro Barcelos, 2350

CEP 90035-903 - Porto Alegre, RS - Brazi

Fone: +55 (51) 3359.8847

Fax: +55 (51) 3359.8760

E-mail: schneiderac@gmail.com 